\title{
Effect of Laser Welding Parameters on Formation of NiTi Shape Memory Alloy Welds
}

\author{
Wei Wang, ${ }^{1,2}$ Xiaohong Yang, ${ }^{1}$ Hongguang Li, ${ }^{2}$ Fuzhong Cong, ${ }^{2}$ and Yongbing Liu ${ }^{1}$ \\ ${ }^{1}$ College of Materials Science and Engineering, Jilin University, Changchun 130012, China \\ ${ }^{2}$ Aviation University of Air Force, Changchun 130022, China \\ Correspondence should be addressed to Yongbing Liu; yongb_liu@163.com
}

Received 30 December 2013; Revised 11 March 2014; Accepted 13 March 2014; Published 3 April 2014

Academic Editor: Kean Aw

Copyright (c) 2014 Wei Wang et al. This is an open access article distributed under the Creative Commons Attribution License, which permits unrestricted use, distribution, and reproduction in any medium, provided the original work is properly cited.

\begin{abstract}
In this work experimental trials of welding of NiTi flat plates with $2.0 \mathrm{~mm}$ thickness were conducted using a $4.5 \mathrm{~kW}$ continuous wave (CW) Nd:YAG laser. The influences of laser output power, welding speed, defocus amount and side-blow shielding gas flow rate on the morphology, welding depth and width, and quality of the welded seam were investigated. Meanwhile, the effects of heat input on the mechanical and functional properties of welded joints were studied. The results show that laser welding can take better formation in NiTi alloys. The matching curves with laser power and welding speed affecting different formation of welds were experimentally acquired, which can provide references for laser welding and engineering application of NiTi alloy. The heat input has obvious effects on the ultimate tensile strength (UTS) and shape memory behavior of the welded joints.
\end{abstract}

\section{Introduction}

NiTi shape memory alloys (SMA) can offer the best combination of functional properties in several shape memory effects (SME) and pseudoelasticity (PE) applications [1]. Due to the low formability alloys, a suitable joining technique must be found to obtain devices and components with complex geometries. Only a few welding techniques for joining NiTi alloys are reported in the literature [2-5]. In recent years the laser has been successfully introduced as a suitable joining technique for NiTi plates. In particular, the Nd:YAG source is suitable for welding low thickness components due to its high precision and reduced HAZ [4]. Moreover, appropriate control of the process parameters can ensure good reproducibility of the results [6].

The effects introduced by the weld on the martensitic transformation will depend both on the microstructure of the reference material and on the welding process parameters. Before the laser welding technology is widely used for NiTi shape memory alloy (SMA), a deeper understanding needs more data on welding process parameters and unfortunately very few experimental comparisons on the welding process parameters are reported [4, 6-9]. A large number of experiments on the welding process parameters would need to be measured to generalize regularities.

In this paper, $2.0 \mathrm{~mm}$ thickness $\mathrm{NiTi}$ flat plates have been tested for butt welding by Nd:YAG laser. The aim of this experimental work is to explore the possibility of welding of NiTi SMA with different welding process parameters, accumulate database, and enlarge the application scope of laserwelding technology. Meanwhile, the laser welding for other SMA materials would benefit from the process regularities acquired through the experiments.

\section{Experimental Details}

Ti-50.9at.\%Ni sheets about $2 \mathrm{~mm}$ in thickness were used throughout this investigation. The sheets were produced by cold rolling and successive ageing by heat treatment at $850^{\circ} \mathrm{C}$ for 30 minutes in pure argon atmosphere.

Before welding, any oxide layers and contamination were removed from the surfaces of the plates. In particular, the surfaces for welding were cleaned with acetone and ethanol 


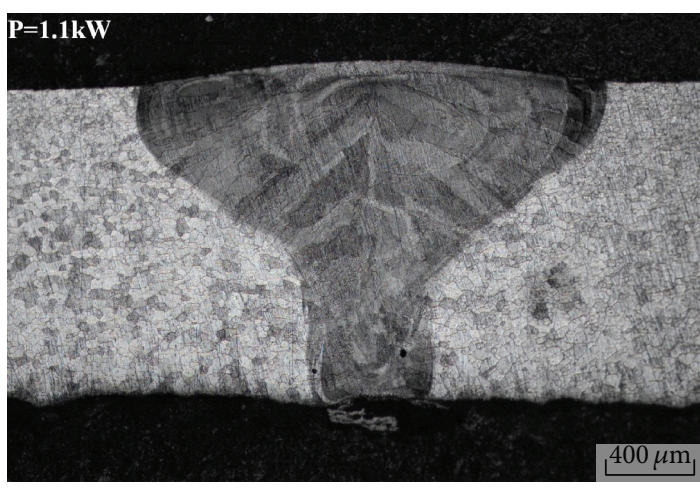

(a) $P=1.1 \mathrm{~kW}$

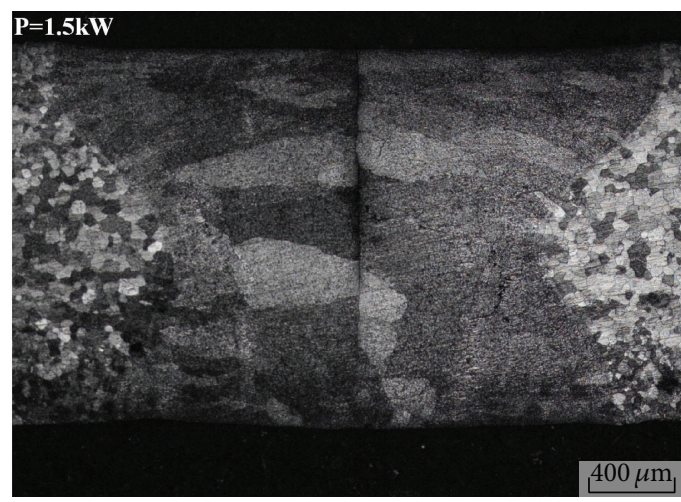

(c) $P=1.5 \mathrm{~kW}$

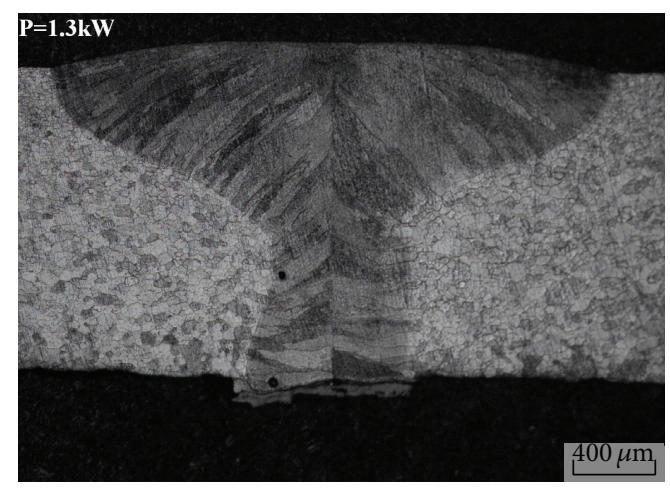

(b) $P=1.3 \mathrm{~kW}$

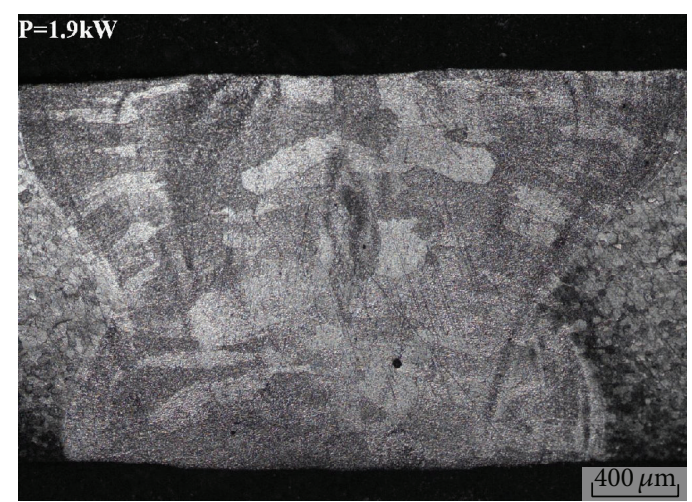

(d) $P=1.9 \mathrm{~kW}$

FIGURE 1: Influence of laser output power on cross-section morphologies of welded seam. $\left(\Delta Z=0 \mathrm{~mm} ; V=1.5 \mathrm{~m} / \mathrm{min} ; U_{f}=15 \mathrm{~L} / \mathrm{min}\right)$.

and then dried. The welding process was carried out using a Nd:YAG laser source (Gsi Lumonics AM356, $4.5 \mathrm{~kW}$ ) operating in continuous wave $(\mathrm{CW})$. One kind of special shielding equipment, made of copper, was prepared to protect the welding zone against possible reaction between the molten metals and ambient air and to avoid the material overheating. Flow of high-purity argon gas can pass through the molten pool from top, back, and lateral sides. Metallographic sample of the welded seam was prepared using standard mechanical polishing procedures and etched in $\mathrm{HF}: \mathrm{HNO}_{3}: \mathrm{H}_{2} \mathrm{O}$ solution in volume ratio of $1: 3: 10$. Microstructure of the welded seam was characterized by Olympus optical microscopy.

The employed parameters were optimized based on our experimental work; that is, laser output power was varied between $1 \mathrm{~kW}$ and $3.5 \mathrm{~kW}$, laser beam scanning velocity varied between $0.9 \mathrm{~m} / \mathrm{min}$ and $3 \mathrm{~m} / \mathrm{min}$, and direction of the side-blow shielding gas was pointed to the opposite welding direction, with an angle of $35^{\circ}$ to the horizon plane, flow rate of side-blow shielding gas of $5 \sim 25 \mathrm{~L} / \mathrm{min}$, and defocus amount of $-3 \sim 2 \mathrm{~mm}$. If the focus point is above the surface of the workpiece, the defocus amount is positive; if below, the defocus amount is negative.

The experiments were designed to study the influences of each parameter on the weld quality when other parameters were kept constant. Using the experiments we can acquire the optimized parameters for high quality full penetration welded joint.
Besides the above, we defined the laser output power as $P$, welding speed as $V$, side-blow shielding gas flow rate as $U_{f}$, defocus amount as $\Delta Z$, the cap width as $W_{u}$, the root width as $W_{b}$, and the weld penetration as $H_{p}$, respectively.

In order to study the effects of heat input on the mechanical and functional properties of welded joints, stress-strain behavior and shape memory behavior were evaluated by uniaxial quasistatic tensile tests and mechanical cycles, which were carried out in the following way: (a) strain controlled uniaxial loading at a strain rate of $0.04 / \mathrm{min}$ up to a total strain $\varepsilon_{t}=8 \%$; (b) complete unloading at the same rate and recording the permanent strain $\varepsilon_{P}$.

\section{Results and Discussions}

3.1. Influence of Laser Output Power. Experimental observation showed that the morphology of the cross sections of the welded seams was asymmetric and changing from $\mathrm{T}$ shape and $\mathrm{V}$ shape to $\mathrm{X}$ shape with the increasing of the output power of laser. Different morphologies can be seen clearly in Figure 1.

Figure 2 indicated that both depth and width increased with the increasing of laser output power. A higher output power was naturally expected to increase the input energy imposed on the welded seam, hence causing a comparatively large amount of melted or vaporized metal [10, 11]. By observing the cross section of the welded seam, it was clear 


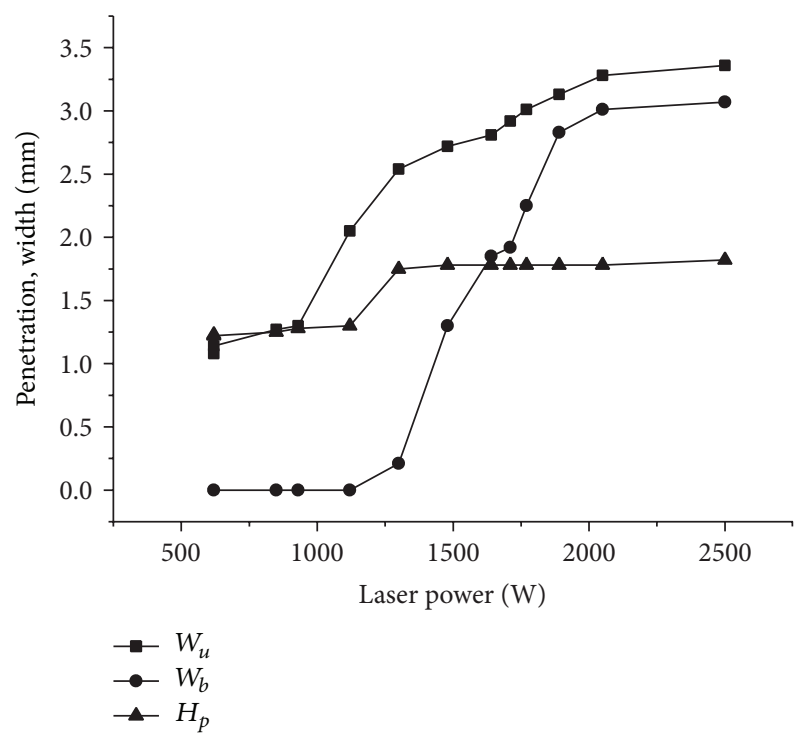

FIGURE 2: Influence of laser output power on width and penetration of welded seam. $\left(\Delta Z=0 \mathrm{~mm} ; V=1.5 \mathrm{~m} / \mathrm{min} ; U_{f}=15 \mathrm{~L} / \mathrm{min}\right)$.

that full penetration welding occurred within the laser output power range of $1.5 \sim 1.9 \mathrm{~kW}$, while partial fusion occurred within the range of $1.1 \sim 1.5 \mathrm{~kW}$ and with welding speed of $1.5 \mathrm{~m} / \mathrm{min}$.

3.2. Influence of Welding Speed. Experimental observation showed that the cross-section morphology of welded seams was asymmetric and changing from $\mathrm{T}$ shape and $\mathrm{V}$ shape to $\mathrm{X}$ shape with the decreasing of the laser scan speed, which changed with the decreasing of the laser scan speed. Different morphologies can be seen clearly in Figure 3.

Figure 4 expressed that welding depth and width change with the laser scan speed. It was noted that the welding depth and width were decreased with the increase of the laser scan speed. Because the welding speed matches opposite with the heat input, the increase of welding speed means the decrease of input energy per unit weld length exerted on the welding line, producing a small amount of intermixed melt and finally a thinner welding depth and narrower width [12].

Through observing the cross section of the welded seam, a full penetration welding occurred within the speed range of $1.8 \sim 1.2 \mathrm{~m} / \mathrm{min}$, while partial fusion occurred in the range of $2.1 \sim 3 \mathrm{~m} / \mathrm{min}$ and with laser output power of $1.5 \mathrm{~kW}$.

3.3. Influence of Defocus Amount. Experimental observation showed that the cross-section morphology of welded seams was asymmetric and changing from $\mathrm{T}$ shape and $\mathrm{X}$ shape to $\mathrm{T}$ shape with the defocus amount variation. Different morphologies can be seen clearly in Figure 5.

Figure 6 indicated that the welding depth and width varied with defocus amount. Power density exerted on the workpiece depends on both the laser beam's power density and the relative amount between the surface of the workpiece and the focus plane. Of course, different defocus amount represents different power density exerted on the workpiece by laser. As shown in Figure 6, full penetration occurred under the defocus amount range of $-2 \sim 3 \mathrm{~mm}$, while partial fusion occurred for $-3 \sim-2 \mathrm{~mm}$ and $+3 \mathrm{~mm}$. The welding width increased with the decreasing of absolute value of defocus amount. Based on the laser beam transfer characteristics, it is known that the laser spot is the smallest in the focus plane and the power density is the largest. The laser beam gradually diverged away from the focus point. For the positive defocus amount, the laser beam enters the keyhole diverged gradually and induces decreased power density and welding depth, while for the negative defocus amount, the laser beam enters the keyhole converged gradually to the focus point and imposes higher power density than that of the surface of the workpiece, favoring more strong melting and vaporization, facilitating the transfer of the laser energy to more depth, and thus deeper welding depth. Nevertheless, the dimension of the laser spot increases sharply, changing the space distribution of the laser power density, thus decreasing the welding depth. With the increase of positive and negative defocus amount, the spot area irradiated on the facade side of the welding seam increased, inducing the increase of melted metal.

3.4. Influence of Side-Blow Shielding Gas Flow Rate. Experimental observation showed asymmetric welded seams and reflected the influence of side-blow shielding gas flow rate on formation of welded seam. According to the various sideblow shielding gas flow rate, different morphologies can be seen clearly in Figure 7.

Figure 8 showed that the welding depth and width change with various side-blow shielding gas flow rates. The gas flow rates from left to right are $25 \mathrm{~L} / \mathrm{min}, 20 \mathrm{~L} / \mathrm{min}, 15 \mathrm{~L} / \mathrm{min}$, $10 \mathrm{~L} / \mathrm{min}$, and $5 \mathrm{~L} / \mathrm{min}$. When the gas flow rate was below $5 \mathrm{~L} / \mathrm{min}$, the weld metal became oxidized and the protection effect was bad; when it was over $10 \mathrm{~L} / \mathrm{min}$, the surface of weld appeared silvery white and the protective effectiveness was very good. With the increase of the side-blow shielding gas flow rate, the weld width was a little narrowed down and the roughened surface and uneven formation were shown. The protective effectiveness and the weld formation was the best as side-blow shielding gas flow rate was $15 \mathrm{~L} \sim 20 \mathrm{~L} / \mathrm{min}$. The above-mentioned considerations underline that the shielding gas plays an important role on the formation of weld. On the other hand, the experiments demonstrate that high gas flow rates yield progressively unstable laser arc; in particular, they do not affect significantly bead geometry and bead depths.

3.5. Effect of Laser Power and Welding Speed on Formation of Weld. Figure 9 showed the effect of two main welding parameters, laser power and welding speed, on the formation of the weld. With the laser power increasing, the type of weld formation changed from partial fusion to full penetration and to excessive penetration finally. With a certain laser power different welding speed can lead to different formation of the weld. Among three types of weld formation, partial fusion and excessive penetration are undesired in practical application. The matching curves were experimentally acquired, which can provide references for laser welding and engineering application of NiTi alloy. 


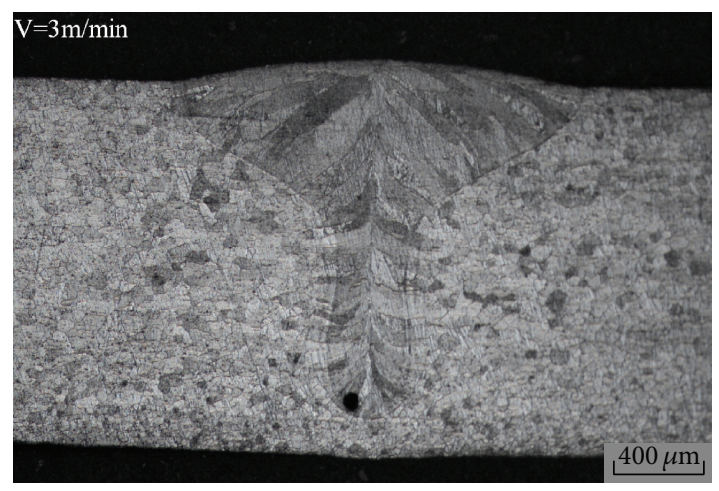

(a) $V=3 \mathrm{~m} / \mathrm{min}$

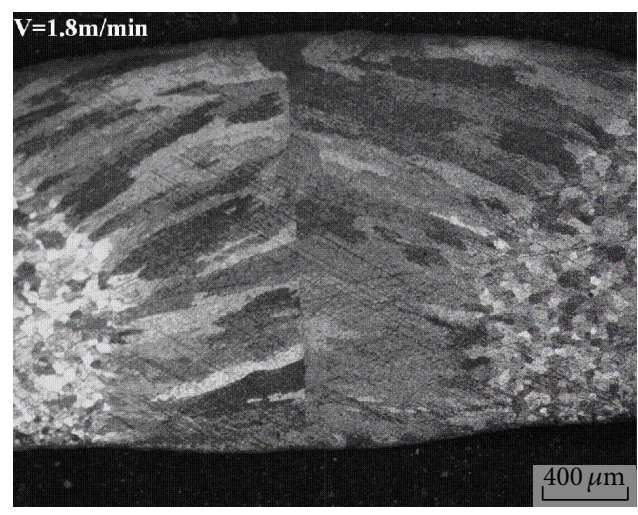

(c) $V=1.8 \mathrm{~m} / \mathrm{min}$

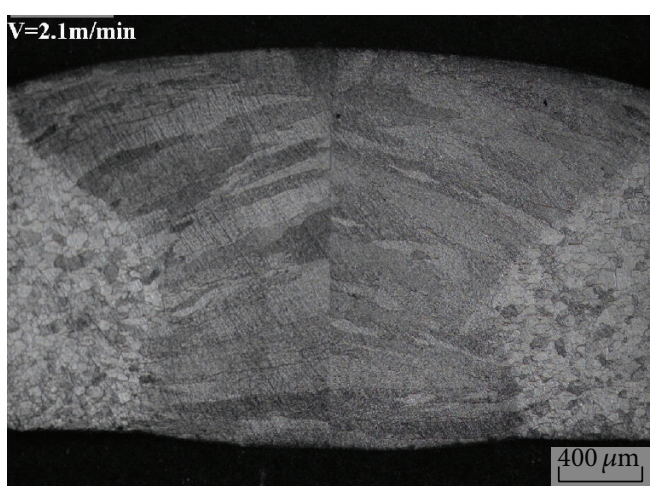

(b) $V=2.1 \mathrm{~m} / \mathrm{min}$

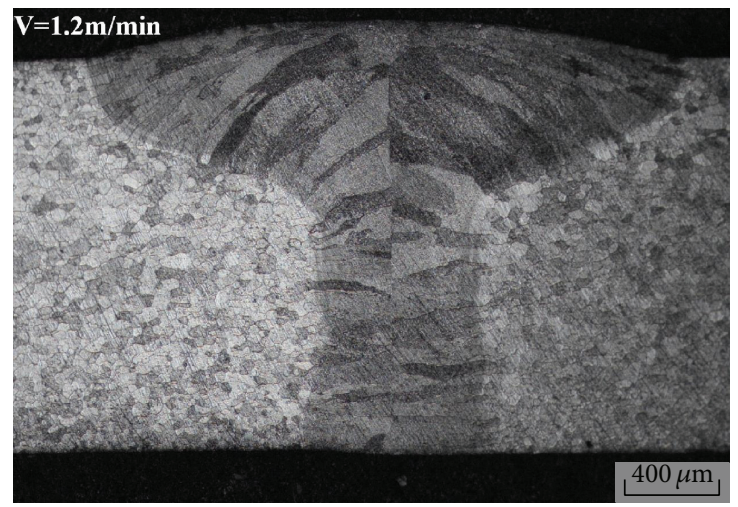

(d) $V=1.2 \mathrm{~m} / \mathrm{min}$

FIGURE 3: Influence of welding speed on cross-section morphologies of welded seam. ( $\left.\triangle Z=0 \mathrm{~mm} ; P=1.5 \mathrm{~kW} ; U_{f}=15 \mathrm{~L} / \mathrm{min}\right)$.

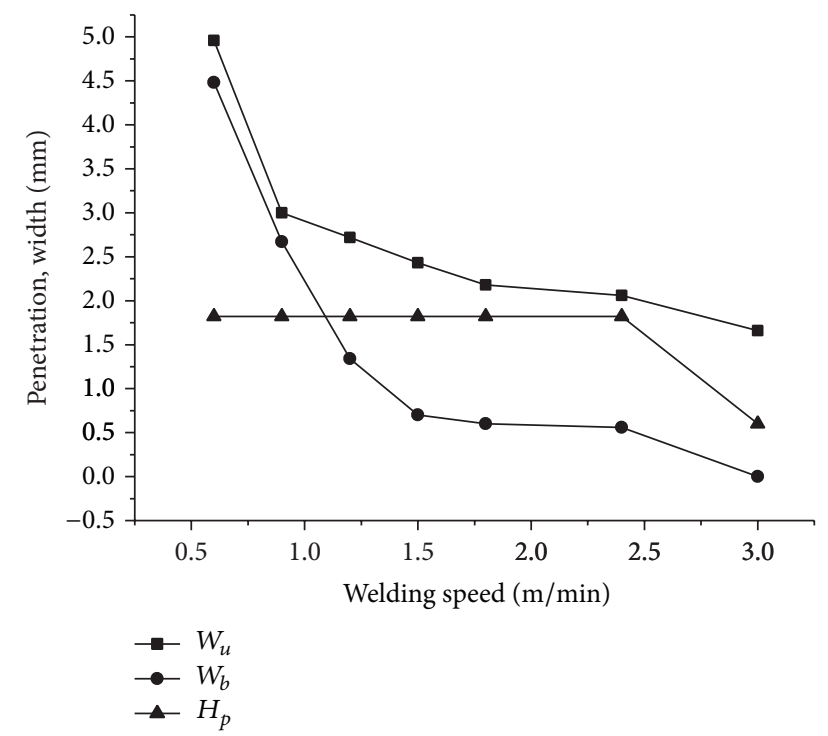

FIGURE 4: Influence of welding speed on width and penetration of welded seam. ( $\left.\Delta Z=0 \mathrm{~mm} ; P=1.5 \mathrm{~kW} ; U_{f}=15 \mathrm{~L} / \mathrm{min}\right)$.

3.6. Effect of Heat Input on Tensile Properties. The heat input is directly related to the laser power, welding speed, and welding efficiency. It can be calculated from heat input $E=(P / V) \times \eta$, where $\eta$ is the welding efficiency. For the same material and welding process, the efficiency will not change. For simplicity, $\eta$ can be assumed as a constant of approximate value 1 . So, it is clear that if the $P$ increases or $V$ decreases, the weld heat input will increase. That is to say, the heat input can be adjusted with the change of the laser power or welding speed. In order to evaluate the modification caused by welding in the stressstrain behavior of the material, standard tensile tests were carried out for full penetration samples.

Table 1 and Figure 10 showed that the tensile properties of the welded joints had a little difference with different heat input. The reason might be that welded joints have different microstructure. When the heat input is high, welding area melts completely. The grains are uniform and fine. So the tensile properties are relatively high. When the heat input is medium, the grains in the welding zone are columnar grains and exhibit poor strength. When the heat input is low, the fusion method belongs to heat conduction. So the strength is better than coarse columnar grains. Because the weld metal has a typical cast structure, its strength and elongation are much lower than that of the rolled base metal. Based on the above analyses, it can be concluded that the larger the heat input, provided that full penetration occurs, the higher the tensile properties of welded joints.

3.7. Effect of Heat Input on Functional Properties. Figure 11 showed the mechanical cycles up to $8 \%$ in terms of stressstrain curves for the three full penetration samples. By 


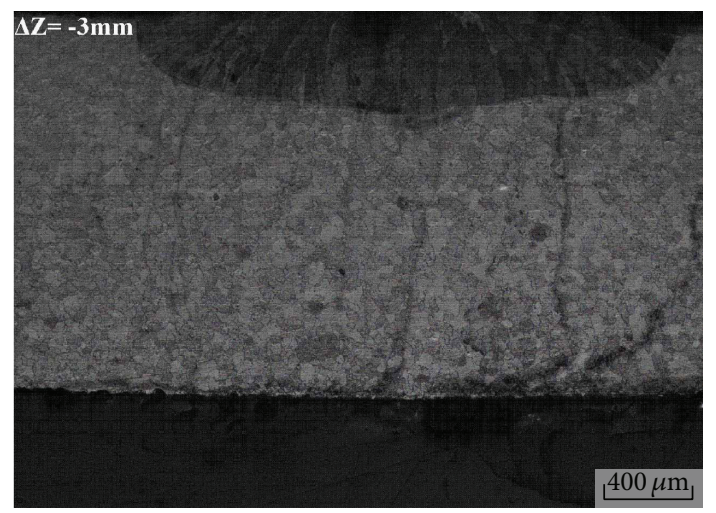

(a) $\Delta Z=-3 \mathrm{~mm}$

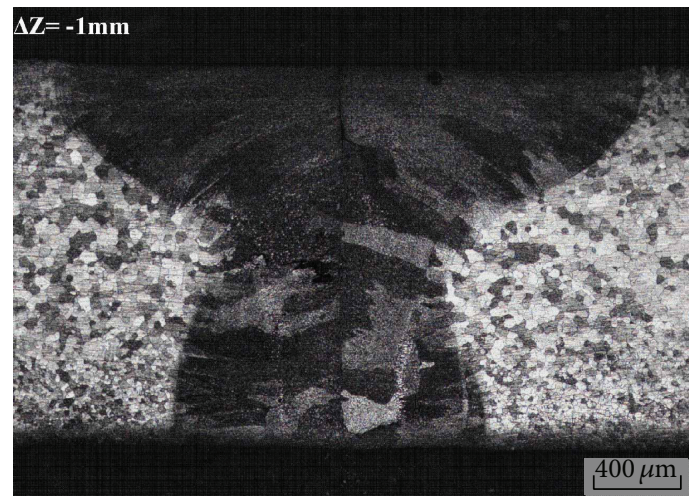

(c) $\Delta Z=-1 \mathrm{~mm}$

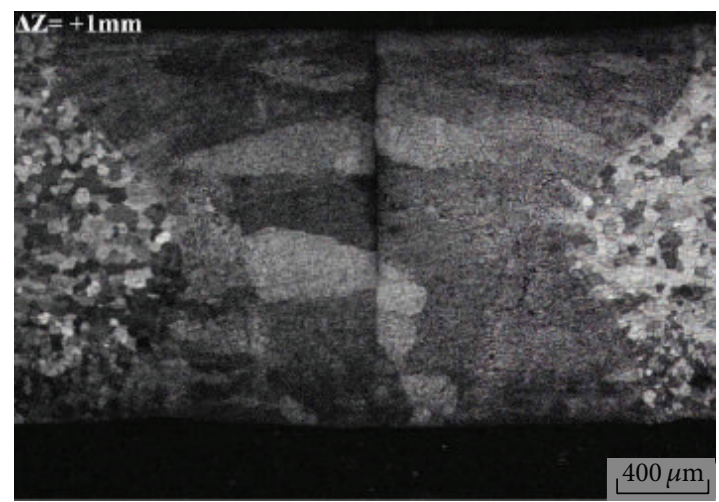

(e) $\Delta Z=+1 \mathrm{~mm}$

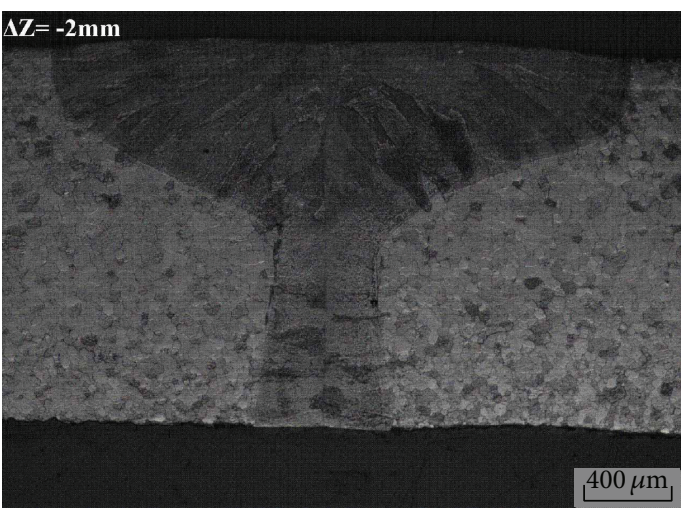

(b) $\Delta Z=-2 \mathrm{~mm}$

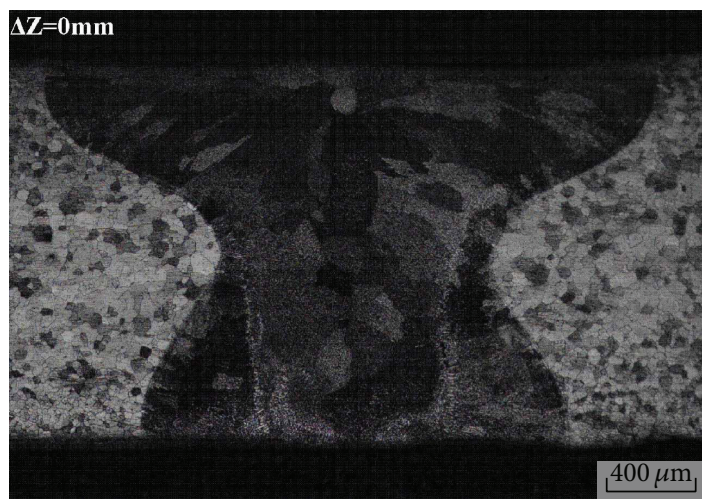

(d) $\Delta Z=0 \mathrm{~mm}$

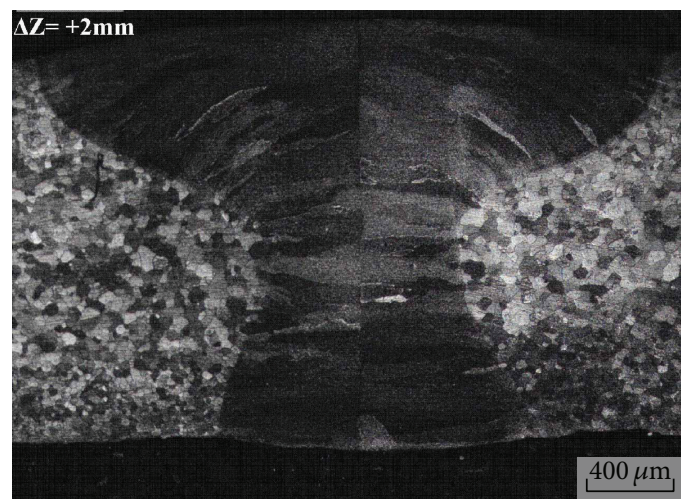

(f) $\Delta Z=+2 \mathrm{~mm}$

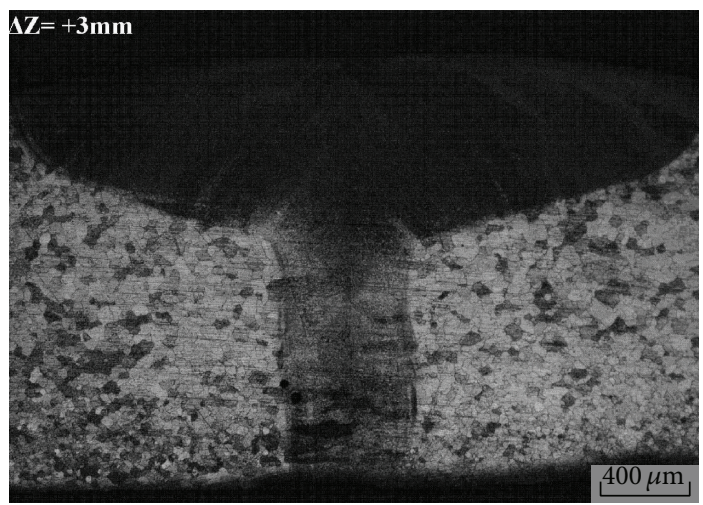

(g) $\Delta Z=+3 \mathrm{~mm}$

FIGURE 5: Influence of defocus amount on cross-section morphologies of welded seam. $\left(P=1610 \mathrm{~W} ; V=1.5 \mathrm{~m} / \mathrm{min} ; U_{f}=15 \mathrm{~L} / \mathrm{min}\right)$. 
TABLE 1: UTS and elongation of the welded joints.

\begin{tabular}{lcccc}
\hline Full penetration samples number & Sample 1 & Sample 2 & Sample 3 & Base material \\
Heat input $(\mathrm{J} / \mathrm{mm})$ & 54.8 & 64 & 70.4 & 1100 \\
UTS $(\mathrm{MPa})$ & 503 & 450 & 531 & 7.9 \\
Elongation $(\%)$ & 4.1 & 5.1 & 4.9 & 7 \\
\hline
\end{tabular}

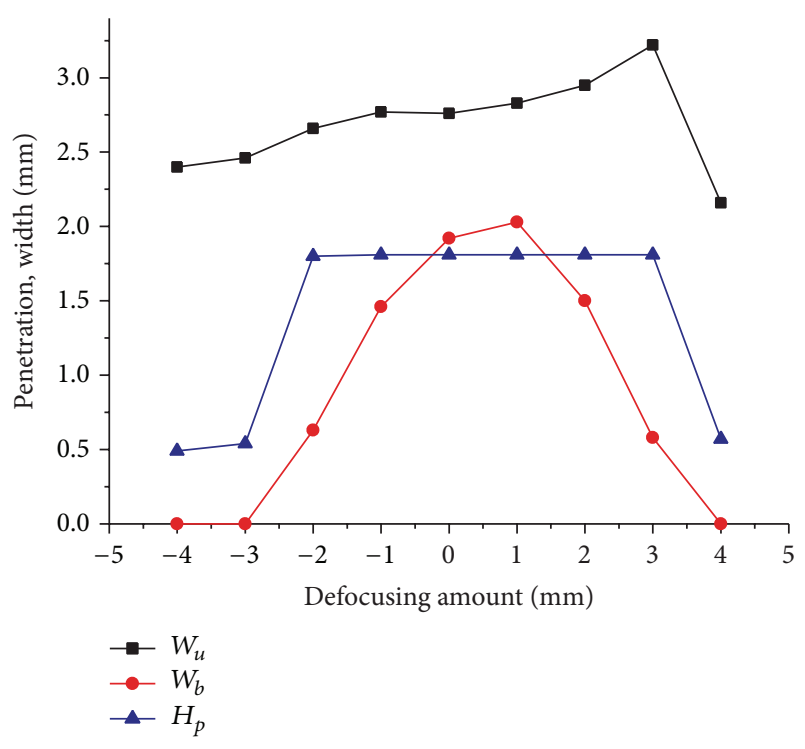

FIGURE 6: Influence of defocus amount on width and penetration of welded seam. $\left(P=1610 \mathrm{~W} ; V=1.5 \mathrm{~m} / \mathrm{min} ; U_{f}=15 \mathrm{~L} / \mathrm{min}\right)$.

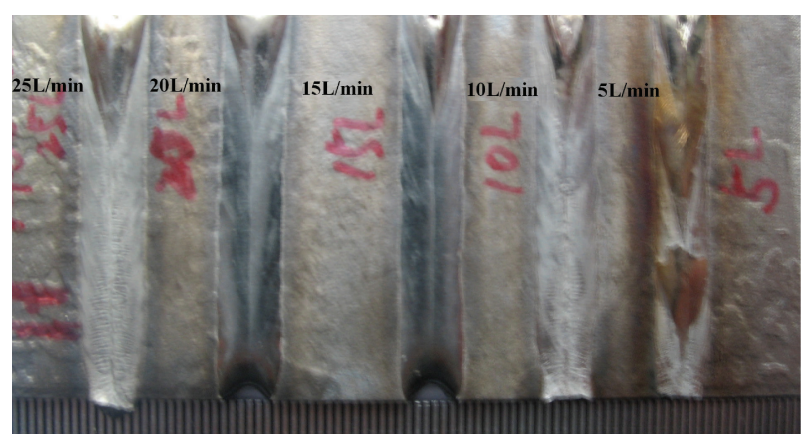

FIGURE 7: Influence of side-blow shielding gas flow rate on formation of welded seam. $(P=1.5 \mathrm{~kW} ; V=0.9 \mathrm{~m} / \mathrm{min} ; \Delta Z=0 \mathrm{~mm})$.

comparing the stress-strain measurements of the weld, the permanent deformation value of the weld was recorded. The $\varepsilon_{P}$ value of sample 3 with high heat input is $1.92 \%$. The $\varepsilon_{P}$ value of sample 2 with medium heat input is $3.02 \%$. The $\varepsilon_{P}$ value of sample 1 with low heat input is $2.42 \%$. The trends of the strain recovered for SME and permanent deformation for three welded samples indicated that high heat input led to smaller residual deformation. The reason for that might be the same with the effects of heat input on tensile properties.

\section{Conclusions}

In order to obtain a stable and efficient NiTi laser welding process, the effects of welding parameters including laser

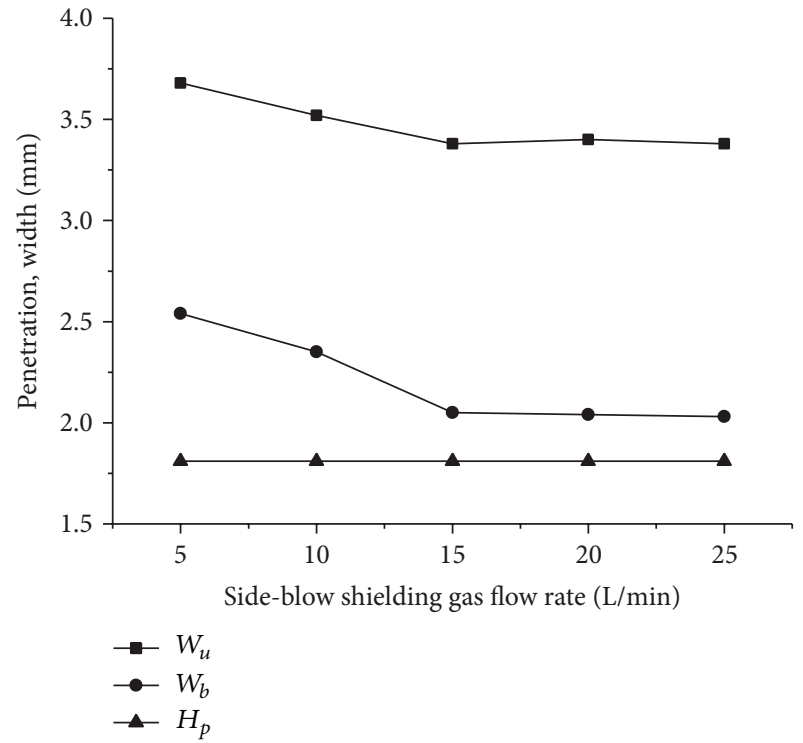

FIGURE 8: Influence of side-blow shielding gas flow rate on width and penetration of welded seam. $(P=1.5 \mathrm{~kW} ; V=0.9 \mathrm{~m} / \mathrm{min} ; \Delta Z=$ $0 \mathrm{~mm})$.

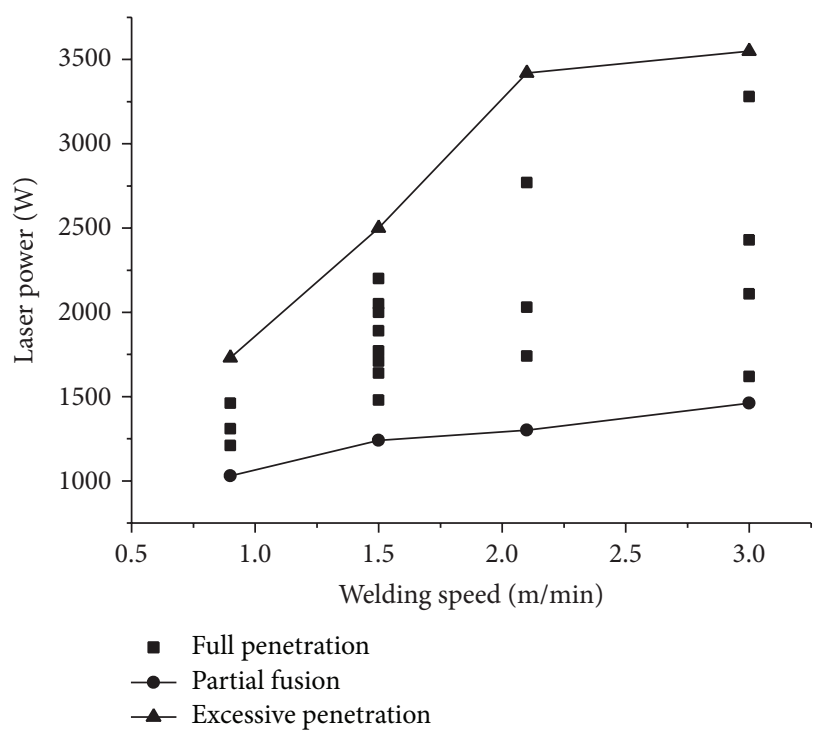

FIGURE 9: Influence of laser power and welding speed on formation of weld. $\left(P=1030 \sim 3550 \mathrm{~W} ; V=0.9 \sim 3 \mathrm{~m} / \mathrm{min} ; \Delta Z=0 \mathrm{~mm} ; U_{f}=\right.$ $15 \mathrm{~L} / \mathrm{min})$.

power, welding speed, defocus amount, and gas-assisting blowing on weld shaping have been taken into consideration. In addition, the effects of heat input on mechanical and shape memory behavior of the Ti-50.9at.\%Ni alloy were 


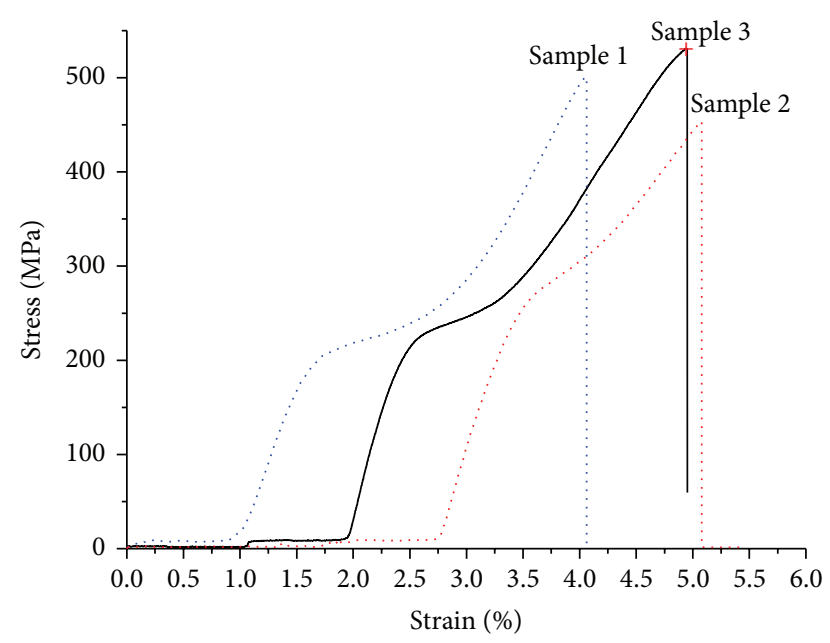

FIGURE 10: Stress-strain curves of the welded material for different heat input.

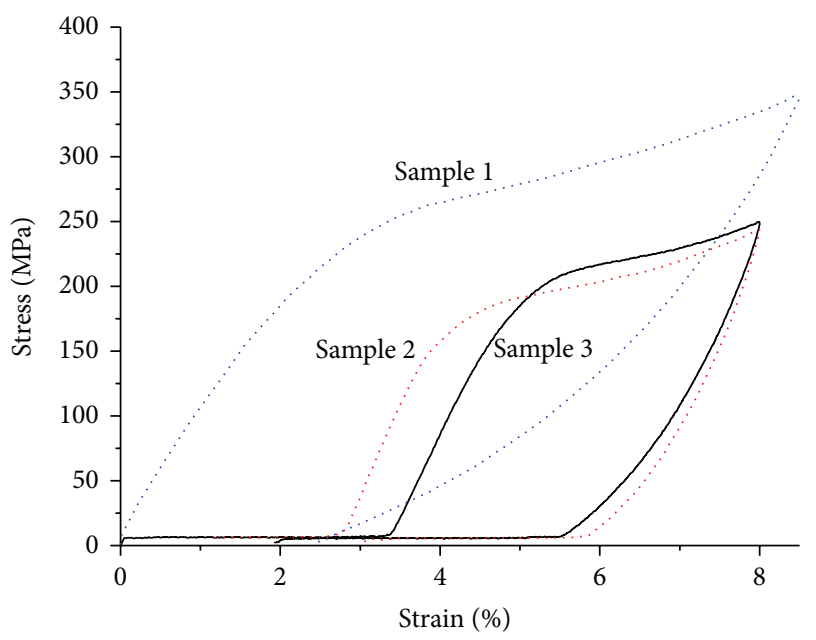

FIGURE 11: Stress-strain cycles with $\varepsilon_{t}$ of about $8 \%$ for different heat input.

investigated. The appropriate matching of main welding parameters is the key to realize the better weld formation.

The defocus amount around $-2 \sim 3 \mathrm{~mm}$ level can lead to full penetration for $2 \mathrm{~mm}$ thick tapes of NiTi alloys. The defocus amount of $0 \sim 1 \mathrm{~mm}$ can obtain optimal formation of the weld.

The protective effectiveness and the weld formation are the best when side-blow shielding gas flow rate keeps at 15 $20 \mathrm{~L} / \mathrm{min}$.

The matching curves with laser power and welding speed affecting different formation of welds were experimentally acquired, which can provide references for laser welding and engineering application of NiTi alloy. The heat input of 54.8 $70.4 \mathrm{~J} / \mathrm{mm}$ can acquire optimal formation of the weld.

For full penetration welded joints, the larger the heat input, the higher the tensile properties and the smaller permanent deformation in strain recovering process. The results showed an obvious reduction in the ultimate tensile strength of the welded material together with a reduction of the elongation to fracture. However, shape memory behavior of the welded joints remains acceptable.

The laser welding can take better formation in NiTi alloys. In the area of thin SMA materials, as well as the materials that are difficult to weld by conventional welding methods, laser welding would play a big role in the future.

\section{Conflict of Interests}

The authors declare that there is no conflict of interests regarding the publication of this paper.

\section{Acknowledgments}

The authors would like to acknowledge the financial support of the Jilin Provincial Science and Technology Department Project (20130101077JC), the Jilin Provincial Science and Technology Department Project (201205009), and the Jilin Provincial Education Department Project (2010015).

\section{References}

[1] C.-W. Chan, Laser micro-welding of a NiTi shape memory alloy for biomedical applications [Ph.D. dissertations], The Hong Kong Polytechnic University, 2008.

[2] A. Tuissi, S. Besseghini, T. Ranucci, F. Squatrito, and M. Pozzi, "Effect of Nd-YAG laser welding on the functional properties of the Ni-49.6at.\%Ti," Materials Science and Engineering A, vol. 273-275, pp. 813-817, 1999.

[3] A. Falvo, F. M. Furgiuele, and C. Maletta, "Laser welding of a NiTi alloy: mechanical and shape memory behaviour," Materials Science and Engineering A, vol. 412, no. 1-2, pp. 235240, 2005.

[4] X. Zhao, W. Wang, L. Chen et al., "Two-stage superelasticity of a Ce-added laser-welded TiNi alloy," Materials Letters, vol. 62, no. 20, pp. 3539-3541, 2008.

[5] C. van der Eijk, H. Fostervoll, Z. K. Sallom, and O. M. Akselsen, "Joining of Specialty Materials," in ASM Materials Solutions Conference \& Exposition, ASM International, Pittsburgh, Pa, USA, 2003.

[6] X. Zhao, W. Wang, L. Chen, F. Liu, J. Huang, and H. Zhang, "Microstructures of cerium added laser weld of a TiNi alloy," Materials Letters, vol. 62, no. 10-11, pp. 1551-1553, 2008.

[7] H. Gugel, A. Schuermann, and W. Theisen, "Laser welding of NiTi wires," Materials Science and Engineering A, vol. 273-275, pp. 149-160, 1999.

[8] H. Rosner, A. V. Shelyakov, A. M. Glezer, and P. Schlobmacher, "On the origin of the two-stage behavior of the martensitic transformation of Ti50Ni25Cu25 shape memory melt-spun ribbons," Materials Science and Engineering A, vol. 307, no. 1-2, pp. 188-189, 2001.

[9] Y. G. Song, W. S. Li, L. Li, and Y. F. Zheng, "The influence of laser welding parameters on the microstructure and mechanical property of the as-jointed NiTi alloy wires," Materials Letters, vol. 62 , no. 15, pp. 2325-2328, 2008.

[10] T. Y. Kuo and H. C. Lin, "Effects of pulse level of Nd-YAG laser on tensile properties and formability of laser weldments in automotive aluminum alloys," Materials Science and Engineering A, vol. 416, no. 1-2, pp. 281-289, 2006. 
[11] X.-B. Liu, M. Pang, Z.-G. Zhang, W.-J. Ning, C.-Y. Zheng, and $\mathrm{G}$. Yu, "Characteristics of deep penetration laser welding of dissimilar metal Ni-based cast superalloy K418 and alloy steel 42CrMo," Optics and Lasers in Engineering, vol. 45, no. 9, pp. 929-934, 2007.

[12] W. Chunming, H. Lunji, and H. Xiyuan, "The relationship between plasma optic signal and penetration depth during partial-penetration laser welding," Laser Technology, vol. 30, pp. 23-26, 2006. 

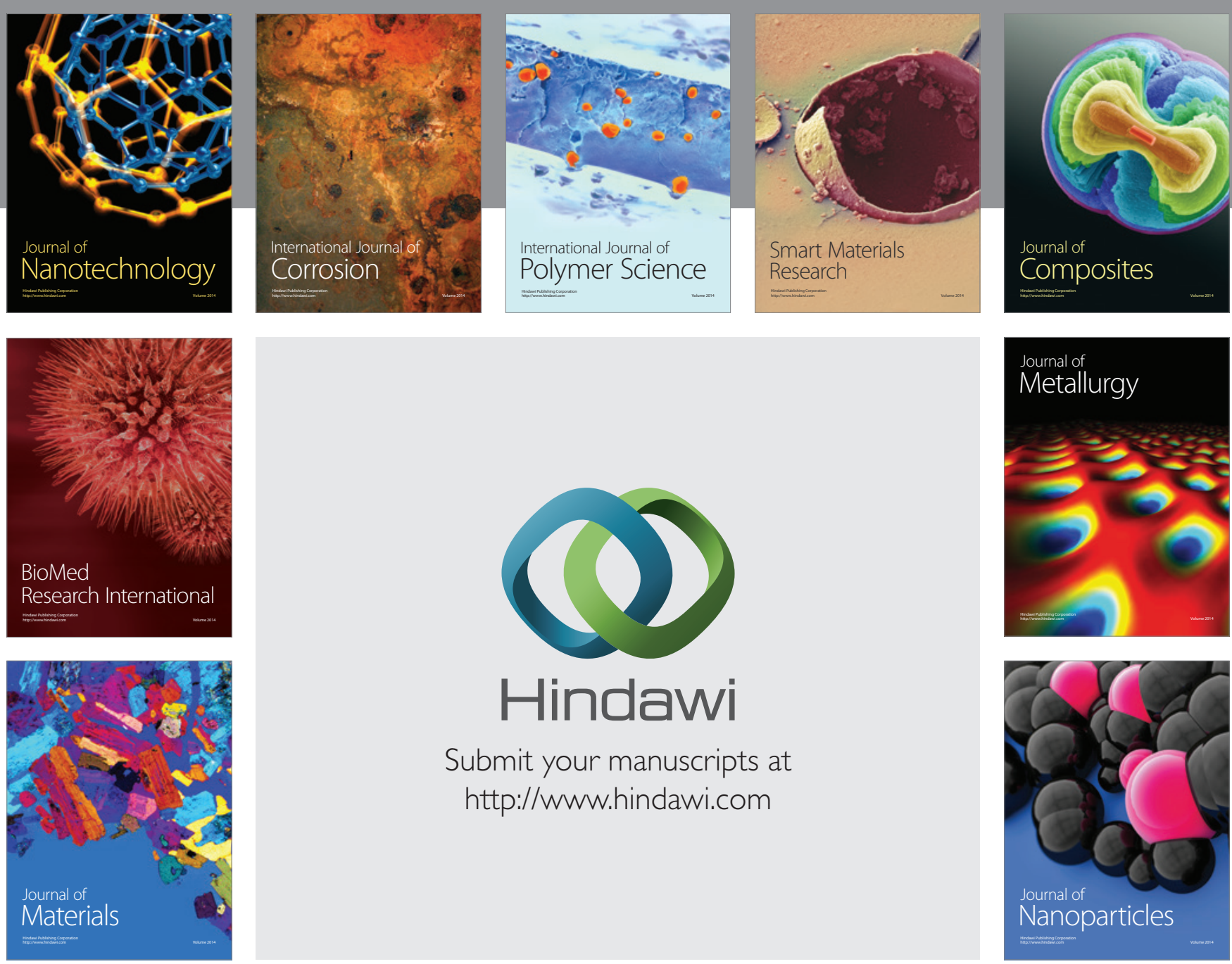

Submit your manuscripts at http://www.hindawi.com
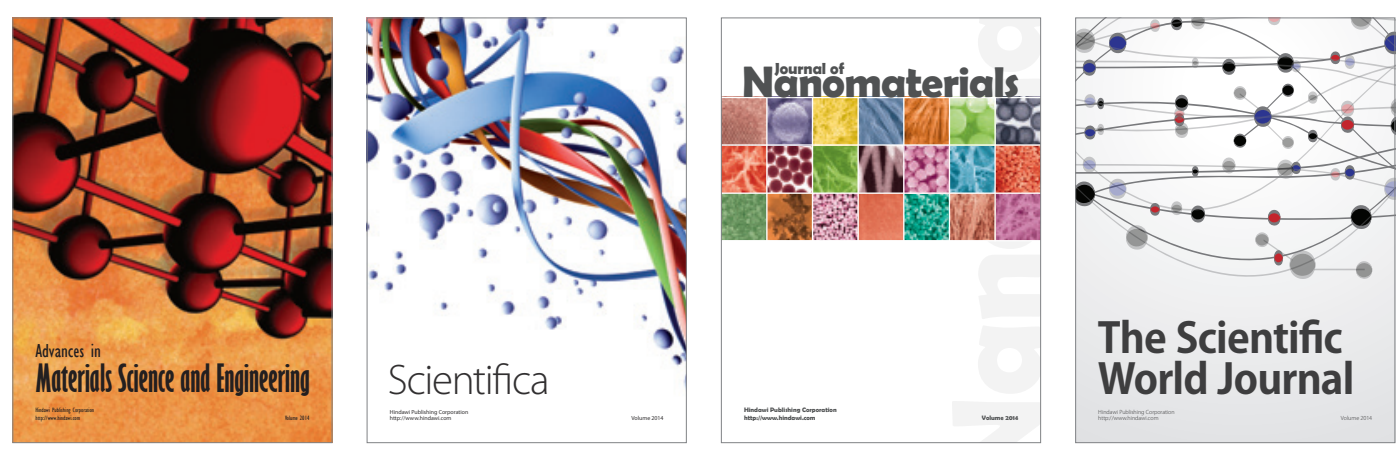

\section{The Scientific World Journal}
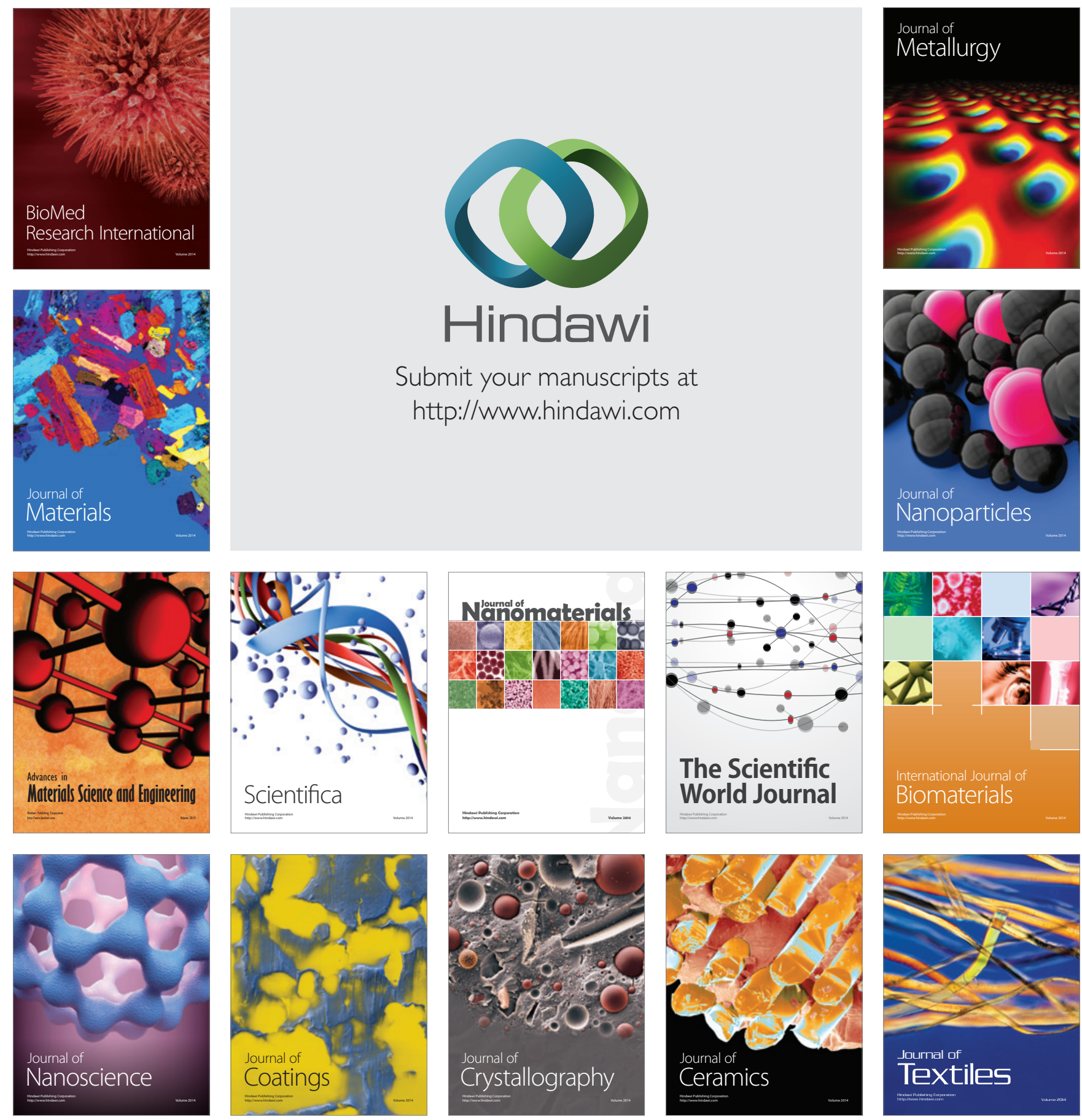